\title{
Analisis Pengaruh Gaya dan Situasi Kepemimpinan Terhadap Iklim Kerja Universitas Halmahera
}

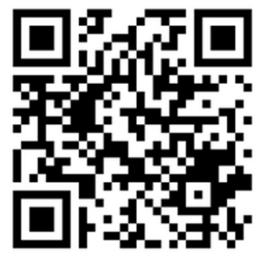

\author{
Jusuf Nikolas Anamofa ${ }^{1}$
}

\begin{abstract}
Abstrak
Tujuan penelitian ini untuk mengetahui pengaruh gaya kepemimpinan terhadap iklim kerja, pengaruh situasi kepemimpinan terhadap iklim kerja, serta pengaruh gaya dan situasi kepemimpinan secara bersama-sama terhadap iklim kerja. Penelitian dilaksanakan di Universitas Halmahera pada tahun 2014 dengan metode survey terhadap 33 orang responden. Data diolah dan dianalisis menggunakan teknik regresi linear sederhana dan regresi linear berganda dengan SPSS versi 17. Hasil penelitian menunjukkan gaya kepemimpinan berpengaruh positif terhadap iklim kerja sebesar $3,8 \%$, situasi kepemimpinan berpengaruh positif terhadap iklim kerja sebesar $6 \%$, dan gaya dan situasi kepemimpinan secara bersama-sama berpengaruh positif terhadap iklim kerja sebesar $6 \%$.
\end{abstract}

Kata Kunci: gaya kepemimpinan, situasi kepemimpinan, iklim kerja

\section{Abstract}

The purpose of this research is to know the influence of leadership style to work climate, influence of leadership situation to work climate, influence of leadership style and leadership situation together to work climate. The study was conducted at Halmahera University in 2014 with a survey method of 33 respondents. Data were processed and analyzed using simple linear regression and simple linear regression technics. The result showed that leadership style had positive effect on work climate, $3.8 \%$, leadership situation had positive effect on work climate, $6 \%$, leadership style and leadership situation together had positive effect on work climate, $6 \%$.

Keywords: leadership style, leadership situation, work climate, Halmahera University

\section{Pendahuluan}

Perguruan Tinggi (PT) adalah organisasi berbasis pengetahuan. Organisasi berbasis pengetahuan dapat dipahami sebagai organisasi yang di dalamnya pengetahuan dijadikan basis pekerjaan setiap orang (Akib, 2012). Seringkali keberadaan suatu organisasi hanya dilihat dari aspek layanan dan produknya saja, tetapi organisasi berbasis pengetahuan akan lebih dipahami berdasarkan proses yaitu aktifitas di dalam organisasi itu, tujuan berupa visi dan misi organisasi itu, serta perspektif dalam pengertian budaya organisasi yang menjamin keberadaan dan keberhasilan suatu organisasi (Michael \& Hall, 2003). Keberadaan dan keberhasilan suatu PT bergantung pada input, proses, output, dan outcome yang harus dapat dikendalikan oleh seorang pemimpin.

Program Studi Pendidikan

Bahasa dan Sastra

Indonesia, STKIP Gotong

Royong Masohi, Jalan Trans

Seram, Masohi - Maluku,

Indonesia)

EMail

jamamova@yahoo.com
Submitted : Oktober 2017

Accepted : Desember 2017

\footnotetext{
JAS-PT

JURNAL ANALISIS SISTEM PENDIDIKAN TINGGI

ISSN 2580 - 5339

Volume 1

Nomor 2

DESEMBER 2017

Hal $53-62$
}

FORUM DOSEN INDONESIA 


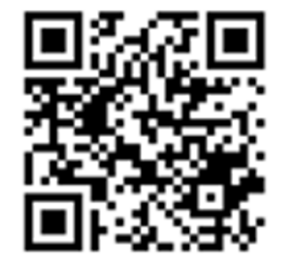

JAS-PT

JURNAL ANALISIS SISTEM PENDIDIKAN TINGGI

ISSN 2580 - 5339

Volume 1

Nomor 2

DESEMBER 2017

Hal $53-62$

FORUM DOSEN INDONESIA
Kegiatan-kegiatan di lingkup PT adalah pelaksanaan Tri Dharma PT, yaitu pendidikan dan pengajaran, penelitian, dan pengabdian kepada masyarakat, serta pengelolaan sumber daya manusia. Mengacu pada kegiatan-kegiatan di lingkup pendidikan tinggi, maka sesungguhnya ada 2 (dua) jenis pemimpin di dalam suatu PT, yaitu: 1) Para pimpinan struktural (academic leaders), yaitu Rektor/Ketua/Direktur dan para stafnya, Dekan dan para stafnya; 2) Para pimpinan ilmu (scientist leaders) yang memimpin kelompok ilmu, dihormati kolega, memiliki kapasitas keilmuan tertentu sehingga punya pengikut di bidang keilmuannya, seperti mahasiswa, peneliti, dan masyarakat umum (Anwar, 2013). Agar para scientist leaders dapat bekerja dalam atmosfer akademik yang baik, maka para structural leaders di PT harus dapat mengelola keragaman keilmuan dan kegiatan-kegiatan yang mendukungnya secara professional dan bertanggung jawab. Dalam perspektif itu, iklim kerja cukup menentukan keberhasilan penyelenggaraan suatu PT.

Universitas Halmahera adalah salah satu PT Swasta di lingkungan Kopertis Wilayah XII, Maluku dan Maluku Utara yang berdiri pada tanggal 22 September 2008. Kampus yang memiliki tigabelas program studi ini visi utamanya adalah menjadi universitas yang handal dan kompetitif dalam mutu pembelajaran dan kekaryaan untuk memajukan ilmu pengetahuan dan teknologi serta seni sebagai sumber air kehidupan dalam meningkatkan peradaban dan kualitas hidup manusia dan alam sekitarnya. Visi itu mesti dicapai dalam suatu suasana yang kondusif di mana salah satu faktor penentunya adalah iklim kerja organisasi.

Dalam konteks Universitas Halmahera, pada tahun 2014, Rektor periode 2010-2014 diberhentikan oleh pihak Yayasan penyelenggara sebelum waktunya. Hal itu berakibat polemik kepemimpinan yang cukup berkepanjangan. Sebelum keputusan Yayasan itu dikeluarkan, penulis mengamati adanya konflik antara rektor dengan pihak yayasan yang perlahan-lahan mengalami eskalasi. Informasi-informasi awal soal gaya dan situasi kepemimpinan rektor yang berpengaruh terhadap beberapa hal termasuk iklim kerja menggerakkan penulis untuk menyelidikinya.

Identifikasi dan perumusan masalah dalam penelitian ini adalah: (a) bagaimana pengaruh gaya kepemimpinan terhadap iklim kerja Universitas Halmahera?; (b) bagaimana pengaruh situasi kepemimpinan terhadap iklim kerja Universitas Halmahera?; (c) bagaimana gaya dan situasi kepemimpinan secara bersama-sama berpengaruh terhadap iklim kerja Universitas Halmahera? Merujuk pada identifikasi masalah tersebut, tujuan penelitian ini adalah untuk mengetahui dan menganalisis pengaruh gaya kepemimpinan terhadap iklim kerja Universitas Halmahera, pengaruh situasi kepemimpinan terhadap iklim kerja Universitas Halmahera, dan pengaruh gaya dan situasi kepemimpinan secara bersama-sama terhadap iklim kerja Universitas Halmahera.

\section{Tinjauan Pustaka}

Penelitian ini dibangun di atas landasan teoretik sebagai berikut:

\section{Gaya Kepemimpinan}

Pemimpin di dalam suatu masyarakat atau organisasi biasanya seseorang yang dianggap mampu memimpin dan mengarahkan masyarakat atau organisasi tersebut ke arah yang dikehendaki bersama. Kemampuan memimpin itulah yang disebut dengan kepemimpinan. Menurut Vetrizal Rivai, kepemimpinan adalah seni mempengaruhi dan mengarahkan orang dengan cara kepatuhan, kepercayaan, kehormatan, dan kerjasama yang bersemangat dalam mencapai tujuan bersama. Oleh karena 
karakteristik memimpin tiap orang berbeda-beda, maka dikenal gaya kepemimpinan yang berbeda antara satu pemimpin dengan yang lainnya. Rivai menyebutkan bahwa gaya kepemimpinan adalah pola menyeluruh dari tindakan seorang pemimpin baik yang tampak maupun yang tidak tampak oleh bawahannya (Fitri \& Syamsir, 2011).

Ada beberapa teori tentang gaya kepemimpinan (Bartrina et al., 2015; Nanjundeswaras \& Swamy, 2014). Salah satu yang patut dipertimbangkan adalah teori Path-Goal yang menyatakan bahwa gaya kepemimpinan terdiri atas kepemimpinan direktif, kepemimpinan suportif, kepemimpinan partisipatif, dan kepemimpinan berorientasi hasil (Luthans, 1989; Polston-Murdoch, 2013), dapat dijelaskan sebagai berikut:

a. Kepemimpinan direktif adalah gaya kepemimpinan yang memiliki hubungan positif dengan harapan dan kepuasan dari mereka yang dipimpin. Pemberian perintahperintah langsung secara lugas dan khusus adalah ciri khas dari gaya kepemimpinan ini. Gaya ini cenderung otoriter dimana orang-orang yang dipimpin tidak pernah berkesempatan untuk mengemukakan pendapat, apalagi berpartisipasi dalam pengambilan keputusan.

b. Kepemimpinan suportif adalah gaya kepemimpinan yang selalu bersedia menjelaskan permasalahan kepada orang-orang yang dipimpin. Pemimpin dengan gaya ini lebih mudah didekati. la akan berusaha memimpin untuk memuaskan hati bawahannya, ramah, peduli, mempertimbangkan kebutuhan bawahan, memperhatikan kesejahteraan. Gaya kepemimpinan ini selalu berupaya meningkatkan motivasi diri orang-orang yang dipimpin dan membuat pekerjaan lebih menarik.

c. Kepemimpinan partisipatif adalah gaya kepemimpinan yang sering meminta dan menggunakan pendapat-pendapat dari orang-orang yang dipimpin untuk mengambil keputusan. Orang-orang yang dipimpin akan merasa sangat dihargai karena dianggap mampu berperan dalam proses-proses pengambilan keputusan.

d. Kepemimpinan berorientasi hasil adalah gaya kepemimpinan yang berusaha menantang para bawahan untuk menunjukkan kinerja secara optimal. Pemimpin akan terus berupaya memperbaiki kinerja dan rasa percaya diri sehingga dipandang oleh bawahan sebagai bentuk tanggung jawab.

\section{Situasi Kepemimpinan}

Teori tentang situasi kepemimpinan menyatakan bahwa tidak ada satu gaya kepemimpinan yang ideal. Akan kelihatan bahwa dalam keadaan tertentu, pemilihan gaya kepemimpinan menjadi efektif atau tidak efektif. Frederick Fiedler memperkenalkan teorinya terkait situasi kepemimpinan dengan nama contingency theory (Papa, Daniels, \& Spiker, 2008). la menyatakan bahwa efektifitas dari suatu gaya kepemimpinan akan dipengaruhi oleh tiga faktor, yaitu:

a. Hubungan pimpinan dengan anggota atau derajat kepercayaan diri dan keyakinan yang dimiliki oleh bawahan terhadap pemimpinnya.

b. Struktur tugas atau derajat dari kepastian pekerjaan dan rutinitas tugas-tugas sebagai kebalikan dari ambiguitas dan ketidakpastian dalam pengerjaan tugas.

c. Posisi kekuasaan atau pengaruh yang termasuk di dalam peran-peran kepemimpinan (legitimasi, kekuasaan, kemampuan untuk memberikan penghargaan atau hukuman).

\section{Iklim Kerja Organisasi}

Iklim kerja organisasi dapat didefinisikan sebagai kenyataan psikologis yang sangat kuat dipengaruhi oleh kondisi-kondisi organisasional, seperti sistem organisasi, struktur

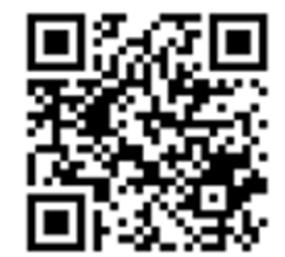

(1)




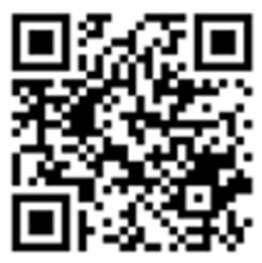

JAS-PT

JURNAL ANALISIS SISTEM PENDIDIKAN TINGG

ISSN 2580 - 5339

Volume 1

Nomor 2

DESEMBER 2017

Hal $53-62$

FORUM DOSEN INDONESIA organsisasi, dan perilaku kepemimpinan. Iklim kerja organisasi adalah persepsi tentang hal-hal yang tercakup dalam lingkup organisasi yang terdiri dari berbagai elemen dan dimensi.

Dimensi-dimensi dari iklim kerja organisasi menurut Litwin dan Stringer adalah: struktur, tanggung jawab, resiko, keramahan, penghargaan, dukungan, standar, konflik, dan identitas (Furnham \& Goodstein, 1997).

\section{Metodologi Penelitian}

Fokus penelitian adalah iklim kerja Universitas Halmahera. Data diperoleh dengan metode survei pada Agustus sampai dengan Oktober 2014. Populasi penelitian adalah para dosen dan pegawai Universitas Halmahera. Penarikan sampel menggunakan teknik Solvin dengan jumlah sampel sebanyak 46 orang. Teknik penarikan sampel proportionate stratified random sampling digunakan terhadap sampel berstrata sehingga diperoleh sampel pada masing-masing strata, yaitu dosen tetap 33 orang dan pegawai tetap 13 orang. Taraf signifikansi $\alpha=5 \%$.

Terdapat 2 variabel bebas yaitu gaya kepemimpinan $\left(X^{1}\right)$ dan situasi kepemimpinan $\left(X^{2}\right)$, serta 1 variabel terikat yaitu iklim kerja $(Y)$. Hipotesis penelitian: (1) gaya kepemimpinan berpengaruh positif terhadap iklim kerja Universitas Halmahera, (2) situasi kepemimpinan berpengaruh positif terhadap iklim kerja Universitas Halmahera, (3) gaya dan situasi kepemimpinan secara bersama-sama berpengaruh positif terhadap iklim kerja Universitas Halmahera.

Skala pengukuran adalah Skala Likert modifikasi 4 poin. Instrumen yang digunakan untuk pengumpulan data adalah instrumen gaya kepemimpinan dengan 4 indikator dan 22 item, instrumen situasi kepemimpinan dengan 3 indikator dan 13 item, dan instrumen iklim kerja organisasi dengan 7 indikator dan 12 item. Teknik analisis data menggunakan statistik parametrik, yaitu (1) regresi linear sederhana untuk memprediksi besaran nilai variabel $(Y)$ yang dipengaruhi oleh variabel $\left(X^{1}\right)$ dan besaran nilai variabel $(Y)$ yang dipengaruhi oleh variabel $\left(X^{2}\right)$, (2) regresi linear berganda untuk memprediksi besaran nilai variabel $(Y)$ yang dipengaruhi oleh variabel $\left(X^{1}\right)$ dan variabel $\left(X^{2}\right)$ secara bersama-sama. Sebelum dianalisis dilakukan uji normalitas data menggunakan test Kolmogorov-Smirnov untuk mengetahui distribusi data. Hasil uji normalitas data menunjukkan seluruh data pada variabel $\left(X^{1}\right),\left(X^{2}\right)$, dan $(Y)$ terdistribusi normal sehingga dapat dianalisis menggunakan statistik parametrik.

\section{Hasil dan Pembahasan}

Ada 2 tahapan analisis yang akan dilakukan yaitu (1) analisis deskriptif untuk memahami tiap variabel secara mandiri baik secara utuh maupun tiap indikator variabelnya, (2) analisis asosiatif untuk memahami hubungan antara tiap variabel yang dihipotesiskan oleh penulis. Tingkat pengembalian kuesioner sebesar $72 \%$ yaitu 33 orang responden. Sebanyak 22 orang menuliskan dengan jelas status sebagai dosen tetap atau pegawai tetap sementara 11 orang tidak memberikan informasi tentang status mereka.

\section{Analisis Deskriptif}

\section{Gaya Kepemimpinan di Universitas Halmahera}

Tabel 1 menunjukkan gaya kepemimpinan Rektor Universitas Halmahera 2010-2014 berada pada kategori sedang, yaitu 56\% dari skor ideal. Gaya kepemimpinan goal oriented cenderung lebih tinggi dari lainnya yaitu sebesar 66\%. Terdapat temuan 
penelitian yang menyatakan bahwa gaya kepemimpinan berorientasi tugas dan hasil akan meningkatkan performa organisasi (Law, 2015), namun hal itu akan berbeda pada populasi yang berbeda (Bahari, Azarnia, Piri, \& Babaeei, 2012).

Tabel 1. Skor Gaya Kepemimpinan

\begin{tabular}{|c|c|c|c|}
\hline Indikator Gaya Kepemimpinan & Total Skor & Skor Ideal & $\%$ \\
\hline Direktif & 548 & 924 & 59 \\
\hline Suportif & 392 & 792 & 49 \\
\hline Partisipatif & 327 & 660 & 50 \\
\hline Goal oriented & 434 & 660 & 66 \\
\hline Total & 1701 & 3036 & 56 \\
\hline
\end{tabular}

Sumber: data primer diolah

\section{Situasi Kepemimpinan di Universitas Halmahera}

Tabel 2 menunjukkan situasi kepemimpinan Universitas Halmahera berada pada kategori sedang, sebesar 49\%. Hubungan pemimpin dengan anggota merupakan aspek yang mendapatkan penilaian paling tinggi, yaitu 53\%. Hal itu menunjukkan bahwa derajat kepercayaan dan keyakinan yang dimiliki oleh bawahan terhadap pimpinannya berada pada level $53 \%$ dari skor ideal.

Tabel 2. Skor Situasi Kepemimpinan

\begin{tabular}{llll}
\hline Indikator Situasi Kepemimpinan & Total Skor & Skor Ideal & $\%$ \\
\hline Hubungan pemimpin dengan & 139 & 264 & 53 \\
anggota & 405 & 792 & 51 \\
$\begin{array}{l}\text { Tugas-tugas } \\
\text { Posisi kekuasaan }\end{array}$ & 302 & 660 & 46 \\
\hline Total & $\mathbf{8 4 6}$ & $\mathbf{1 7 1 6}$ & $\mathbf{4 9}$ \\
\hline
\end{tabular}

Sumber: data primer diolah

\section{Iklim Kerja Universitas Halmahera}

Tabel 3 menunjukkan iklim kerja Universitas Halmahera berada pada kategori kuat, yaitu $62 \%$. Indikator yang mendapat skor tertinggi adalah pertumbuhan kepribadian (71\%) dan kejelasan tujuan pekerjaan (70\%). Hal itu menunjukkan bahwa iklim kerja Universitas Halmahera sangat positif sehingga memungkinkan bagi pertumbuhan kepribadian. Hal itu didukung oleh beberapa temuan yang menyatakan bahwa pertumbuhan kepribadian menunjukkan dinamika organisasi yang positif (Frager, R., \& Fadiman, 2005; Geise, 2008).

Tabel 3. Skor Iklim Kerja

\begin{tabular}{|c|c|c|c|}
\hline Indikator Iklim Kerja & Total Skor & Skor Ideal & $\%$ \\
\hline Otonomi dan fleksibilitas & 87 & 132 & 66 \\
\hline Menaruh kepercayaan dan terbuka & 149 & 264 & 56 \\
\hline Simpatik dan memberi dukungan & 158 & 264 & 60 \\
\hline Jujur dan menghargai & 80 & 132 & 61 \\
\hline Kejelasan tujuan & 184 & 264 & 70 \\
\hline Pekerjaan yang beresiko & 140 & 264 & 53 \\
\hline Pertumbuhan kepribadian & 188 & 264 & 71 \\
\hline Total & 986 & 1584 & 62 \\
\hline
\end{tabular}

Sumber: data primer diolah

62 


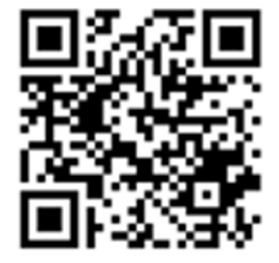

JAS-PT

JURNAL ANALISIS SISTEM PENDIDIKAN TNGG ISSN 2580 - 5339

Volume 1

Nomor 2

DESEMBER 2017

Hal $53-62$

FORUM DOSEN INDONESIA

\section{Analisis Asosiatif}

Hipotesis yang dibangun adalah: (1) gaya kepemimpinan berpengaruh positif terhadap iklim kerja organisasi Univesitas Halmahera, (2) situasi kepemimpinan berpengaruh positif terhadap iklim kerja organisasi Universitas Halmahera, (3) gaya dan situasi kepemimpinan secara bersama-sama berpengaruh positif terhadap iklim kerja organisasi Universitas Halmahera. Pengujian terhadap hipotesis dapat ditunjukkan di bawah ini.

Tabel 4. Statistik Deskriptif

\begin{tabular}{lccc}
\hline & Mean & Std. Deviation & N \\
\hline Iklim kerja & 29.88 & 6.188 & 33 \\
Gaya kepemimpinan & 51.55 & 12.553 & 33 \\
Situasi kepemimpinan & 25.82 & 5.365 & 33 \\
\hline
\end{tabular}

Sumber: data primer diolah

Tabel 4 menunjukkan rata-rata jawaban responden tentang iklim kerja $(Y)$ sebesar 29,88 dengan standar deviasi sebesar 6,188, artinya iklim kerja Universitas Halmahera berkisar antara 29,88 $\pm 6,188$ (rata-rata jawaban bisa bertambah atau berkurang sebesar 6,188 dari $29,8 \overline{8})$. Rata-rata jawaban responden tentang gaya kepemimpinan $\left(X^{1}\right)$ sebesar 51,55 dengan standar deviasi sebesar 12,553, artinya gaya kepemimpinan berkisar antara $51,55 \pm 12,553$ (rata-rata jawaban bisa bertambah atau berkurang sebesar 12,553 dari 51,55 ). Rata-rata jawaban responden tentang situasi kepemimpinan $\left(X^{2}\right)$ sebesar 25,82 dengan standar deviasi sebesar 5,365, artinya situasi kepemimpinan Universitas Halmahera berkisar antara 25,82 \pm 5,365 (rata-rata jawaban bisa bertambah atau berkurang sebesar 5,365 dari 25,82)

Tabel 5. Korelasi

\begin{tabular}{|c|c|c|c|c|}
\hline Keterangan & Variabel & $\begin{array}{l}\text { iklim } \\
\text { kerja }\end{array}$ & $\begin{array}{c}\text { gaya } \\
\text { kepemimpinan }\end{array}$ & $\begin{array}{c}\text { situasi } \\
\text { kepemimpinan }\end{array}$ \\
\hline \multirow{3}{*}{$\begin{array}{l}\text { Pearson } \\
\text { Correlation }\end{array}$} & iklim kerja & 1.000 & .194 & .244 \\
\hline & gaya kepemimpinan & .194 & 1.000 & .821 \\
\hline & situasi kepemimpinan & .244 & .821 & 1.000 \\
\hline \multirow{3}{*}{$\begin{array}{l}\text { Sig. } \\
\text { (1-tailed) }\end{array}$} & iklim kerja & & .140 & .086 \\
\hline & gaya kepemimpinan & .140 & & .000 \\
\hline & situasi kepemimpinan & .086 & .000 & \\
\hline \multirow[t]{3}{*}{$\mathbf{N}$} & iklim kerja & 33 & 33 & 33 \\
\hline & gaya kepemimpinan & 33 & 33 & 33 \\
\hline & situasi kepemimpinan & 33 & 33 & 33 \\
\hline
\end{tabular}

Sumber: data primer diolah

Tabel 5 menunjukkan hasil pengujian hipotesis penelitian yang dapat dijelaskan sebagai berikut:

\section{a. Pengujian Hipotesis 1: Pengaruh Gaya Kepemimpinan Terhadap Iklim Kerja}

Hipotesis 1 menyatakan gaya kepemimpinan Rektor Universitas Halmahera periode 2010-2014 berpengaruh positif terhadap iklim kerja Universitas Halmahera. Dari tabel 6 , hasil perhitungan korelasi antara variabel gaya kepemimpinan $\left(X_{1}\right)$ dengan iklim kerja (Y) diperoleh nilai sebesar $r=0,194$. Nilai itu menunjukkan hubungan yang sangat lemah positif, artinya ada hubungan yang searah antara variabel $\left(X_{1}\right)$ dengan variabel $(Y)$, namun jika variabel $\left(X_{1}\right)$ mengalami perubahan, variabel $(Y)$ kemungkinan besar tidak ikut berubah, walaupun ada kemungkinan kecil untuk berubah secara sangat lemah. Kontribusi yang diberikan oleh variabel $\left(\mathrm{X}_{1}\right)$ terhadap variabel $(\mathrm{Y})$ adalah: $K P=$ 
$(r)^{2} \times 100 \%=(0,194)^{2} \times 100 \%=3,8 \%$. Temuan ini sejalan dengan beberapa temuan lainnya yang menyatakan bahwa gaya kepemimpinan tidak memiliki pengaruh yang signifikan terhadap aspek berorganisasi seperti komitmen berorganisasi (J. Deddy dkk., 2013) dan iklim kerja organisasi (Makaske, Hoogeboom, Wilderom, \& Wilderom, 2015).

\section{b. Pengujian Hipotesis 2: Pengaruh Situasi Kepemimpinan Terhadap Iklim Kerja}

Hipotesis 2 menyatakan situasi kepemimpinan berpengaruh positif terhadap iklim kerja Universitas Halmahera. Dari tabel 6, hasil perhitungan korelasi antara variabel situasi kepemimpinan $\left(\mathrm{X}_{2}\right)$ dengan iklim kerja $(\mathrm{Y})$ diperoleh nilai sebesar $r=0,244$. Nilai itu menunjukkan hubungan yang lemah positif, artinya ada hubungan searah antara variabel $\left(X_{2}\right)$ dengan variabel $(Y)$, jika variabel $\left(X_{2}\right)$ mengalami perubahan, maka variabel $(Y)$ secara lemah ikut berubah. Kontribusi yang diberikan variabel $\left(X_{2}\right)$ terhadap variabel $(Y)$ adalah: $K P=(r)^{2} \times 100 \%=(0,244)^{2} \times 100 \%=6 \%$.

Hasil perhitungan korelasi antara variabel $\left(X_{1}\right)$ dengan $\left(X_{2}\right)$ diperoleh nilai sebesar $r=$ 0,821 . Nilai itu menunjukkan hubungan yang sangat kuat dan positif, artinya ada hubungan yang sangat kuat antara variabel $\left(X_{1}\right)$ dengan variabel $\left(X_{2}\right)$, di mana jika salah satu variabel berubah akan mengakibatkan perubahan yang sangat besar pada variabel lainnya.

Tabel 6. Model Summaryb

\begin{tabular}{lc}
\multicolumn{1}{c}{ Keterangan } & Koefisien \\
\hline R & $0,244^{\mathrm{a}}$ \\
R Square & 0.060 \\
Adjusted R Square & -0.003 \\
Std Error of The Estimate & 6,198 \\
Change Statistics & \\
R Square Change & 0,060 \\
F Change & 0,952 \\
df1 & 2 \\
df2 & 30 \\
Sig. F Change & 0,397 \\
Durbin-Watson & 2.002 \\
\hline
\end{tabular}

a. Predictors: (Constant), situasi kepemimpinan, gaya kepemimpinan

b. Dependent Variable: iklim kerja

\section{c. Pengujian Hipotesis 3: Pengaruh Gaya dan Situasi Kepemimpinan Secara Bersama-sama terhadap Iklim Kerja}

Hipotesis 3 menyatakan gaya kepempimpinan Rektor Universitas Halmahera periode 2010-2014 dan situasi kepemimpinan secara bersama-sama berpengaruh positif terhadap iklim kerja Universitas Halmahera. Hasil korelasi $(R)$ yang secara simultan (bersama-sama) antara variabel gaya kepemimpinan $\left(X_{1}\right)$ dan situasi kepemimpinan $\left(X_{2}\right)$ terhadap iklim kerja $(Y)$ diperoleh nilai sebesar $r=0,244$. Nilai ini menunjukkan hubungan yang lemah positif antara variabel $\left(X_{1}\right)$ dan $\left(X_{2}\right)$ secara simultan terhadap variabel $(Y)$. Kontribusi yang diberikan oleh kedua variabel ini (X1 dan $X 2)$ terhadap variabel $(Y)$ adalah: $K P=\left(r_{\times 1, \times 2, Y}\right)^{2} \times 100 \%=(0,244)^{2} \times 100 \%=6 \%$.

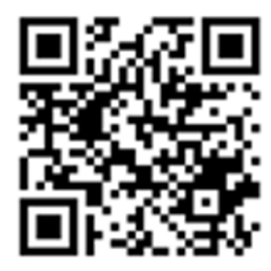




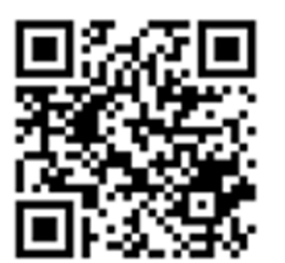

JAS-PT

JURNAL ANALISIS SISTEM PENDIDIKAN TINGG

ISSN $2580-5339$

Volume 1

Nomor 2

DESEMBER 2017

Hal $53-62$

FORUM DOSEN INDONESIA
Tabel 7. ANOVA

\begin{tabular}{|c|c|c|c|c|c|c|}
\hline \multicolumn{2}{|c|}{ Model } & $\begin{array}{l}\text { Sum of } \\
\text { Squares }\end{array}$ & Df & Mean Square & $F$ & Sig. \\
\hline \multirow[t]{3}{*}{1} & Regression & 73.150 & 2 & 36.575 & .952 & $.397^{a}$ \\
\hline & Residual & 1152.365 & 30 & 38.412 & & \\
\hline & Total & 1225.515 & 32 & & & \\
\hline
\end{tabular}

a. Predictors: (Constant), situasi kepemimpinan, gaya kepemimpinan

b. Dependent Variable: iklim kerja

Analisis pada tabel anova digunakan untuk mengetahui apakah model regresi linier berganda dapat digunakan untuk memprediksi besaran nilai iklim kerja organisasi yang dipengaruhi oleh gaya kepemimpinan dan situasi kepemimpinan. Dengan kriteria keputusan yang diambil berdasarkan nilai probabilitas dapat ditentukan jika nilai probabilitas (sig.) < taraf siginifikan a, maka model regresi linier berganda dapat digunakan, tetapi jika (sig.) > a, maka model regresi linier berganda tidak dapat digunakan.

Diketahui dari tabel anova, nilai probabilitas (sig.) $=0,397$ dan nilai taraf signifikan $a=$ 0,05 . Oleh karena nilai probabilitas (sig.) $0,397>$ nilai taraf signifikan a 0,05 , maka dapat diputuskan bahwa model regresi linier berganda tidak dapat digunakan untuk memprediksi nilai besaran iklim kerja Universitas Halmahera yang dipengaruhi oleh gaya kepemimpinan Rektor Universitas Halmahera periode 2010-2014 dan situasi kepemimpinan Universitas Halmahera.

\section{Penutup}

\section{Simpulan}

Simpulan penelitian ini adalah sebagai berikut:

1. Gaya kepemimpinan Rektor Universitas Halmahera periode 2010-2014 berpengaruh positif tetapi sangat lemah terhadap iklim kerja Universitas Halmahera. Hal ini menunjukkan bahwa seperti apapun gaya kepemimpinan rektor, hanya berkontribusi $3,8 \%$ bagi iklim kerja.

2. Situasi kepemimpinan berpengaruh positif tetapi lemah terhadap iklim kerja Universitas Halmahera. Hal ini menunjukkan bahwa seperti apapun situasi kepemimpinan, hanya berkontribusi $6 \%$ bagi iklim kerja.

3. Gaya dan situasi kepemimpinan Universitas Halmahera secara bersama-sama berpengaruh secara positif tetapi lemah terhadap iklim kerja Universitas Halmahera yaitu hanya sebesar $6 \%$.

\section{Pikiran Rekomendatif}

Penelitian ini menunjukkan bahwa kontribusi gaya kepemimpinan Rektor Universitas Halmahera periode 2010-2014 dan situasi kepemimpinan sangat lemah terhadap iklim kerja Universitas Halmahera. Implikasi manajerial di Universitas Halmahera yang perlu diperhatikan, yaitu hasil penelitian ini bisa berdampak negatif, bisa juga positif. Dampak negatifnya adalah ada semacam pengakuan dari para dosen tetap dan pegawai tetap bahwa gaya kepemimpinan rektor tertentu tidak berpengaruh terhadap iklim kerja. Padahal sebagaimana diketahui bahwa seorang pemimpin harus memiliki kemampuan mempengaruhi. Dampak positifnya adalah pimpinan Universitas Halmahera dapat mengupayakan strategi-strategi penguatan pengaruh gaya kepemimpinan dan situasi kepemimpinan terhadap iklim kerja sehingga kontribusinya dapat menjadi besar. 
Dengan memperbesar kontribusi variabel-variabel tersebut, pimpinan universitas dapat secara kreatif mengelola fungsi-fungsi manajerial di bidang pendidikan tinggi.

\section{Daftar Pustaka}

Akib, H., 2012. Membangun Kapabilitas Organisasi Berbasis Pengetahuan. Retrieved from https://haedarakib.files.wordpress.com/2012/10/orasi-ilmiah-membangunkapabilitas-organisasi-berbasis-pengetahuan.doc

Anwar, R., 2013. Kepemimpinan Ideal Pendidikan Tinggi. Retrieved December 17, 2017, from http://mmpt.pasca.ugm.ac.id/home.php?k=9\&j=50

Bahari, S., Azarnia, H., Piri, S., \& Babaeei, E., 2012. Relationship between Leadership Style and Productivity in Public Sport Organizations. European Journal of Experimental Biology, 2(3), 723-725.

Bartrina, S., Tutor, F., Mar, A., Administraci, G. E. N., Ae, D. E. E., Final, T., \& Curso, D. E. G., 2015. The Effects of Leadership and Internal Communication on The Organizational Climater. Retrieved from http://repositori.uji.es/xmlui/bitstream/handle/10234/161390/TFG_2016_Bartrina DeLaFuenteSergi.pdf?sequence=1

Fitri, S. E., \& Syamsir., 2011. Pengaruh Gaya Kepemimpinan terhadap Iklim Kerja Organisasi. Demokrasi, $\quad X(2), \quad 159-174 . \quad$ Retrieved from http://ejournal.unp.ac.id/index.php/jd/article/viewFile/1010/850

Frager, R., \& Fadiman, J., 2005. Personality and Personal Growth (6th ed.), 56. Retrieved from http://www.universityofcalicut.info/SDE/VI Sem.B.Sc.Counselling Psychology- Additional Paper in lieu of Project- Personaliity and Personal Growth.pdf

Furnham, A., \& Goodstein, L. D., 1997. The organizational climate questionnaire (OCQ). The 1997 Annual. Retrieved from http://www.wiley.com/WileyCDA/WileyTitle/productCd-0883904926.html

Geise, A. C., 2008. Personal Growth and Personality Development: Well-being and Ego Development, (August), 1-53. Retrieved from https://mospace.umsystem.edu/xmlui/bitstream/handle/10355/5667/research.pdf

J. Deddy dkk., 2013. Pengaruh gaya kepemimpinan, keselamatan dan kesehatan kerja, kepuasan kerja terhadap komitmen organisasional. Jurnal Profit, 7(2), 127-136. Retrieved from http://ejournalfia.ub.ac.id/index.php/profit/article/download/336/570

Law, M., 2015. Examining task and relationship-oriented leadership styles: an in-class application activity. Journal of Academic and Business Ethics, 10, 1-6. Retrieved from http://www.aabri.com/manuscripts/152366.pdf

Luthans, F., 1989. Organizational behavior (5th ed.). Organizational behavior (5th ed.). Retrieved from http://search.ebscohost.com/login.aspx?direct=true\&db=psyh\&AN=1989-98511000\&lang=de\&site=ehost-live

Makaske, I., Hoogeboom, D. A. M. G. M., Wilderom, C., \& Wilderom, C. P. M., 2015. The effect of leadership behavior on work climate and team effectiveness. Retrieved from http://essay.utwente.nl/67485/1/Makaske_BA_faculty.pdf.pdf

Michael, H., \& Hall, H., 2003. What Is a Knowledge-Based Organization? Theme:

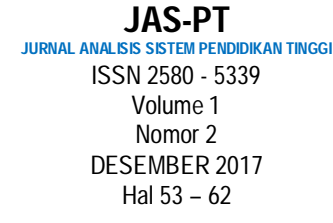

FORUM DOSEN INDONESIA 


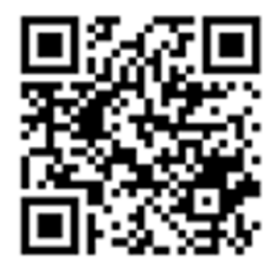

Strategy, Competitiveness and Learning, 1-7.

Nanjundeswaras, T. S., \& Swamy, D. R., 2014. Leadership Styles. Advances in Management, 7(2), 57-63. https://doi.org/10.1016/B978-1-84334-658-6.50003-6

Papa, M. J., Daniels, T. D., \& Spiker, B. K., 2008. Leader-Member Relationships. In Organizational Communication: Perspectives and Trends (pp. 259-290). 2455 Teller Road, Thousand Oaks California 91320 United States: SAGE Publications, Inc. https://doi.org/10.4135/9781483329239.n10

Polston-Murdoch, L., 2013. An Investigation of Path-Goal Theory , Relationship of Leadership Style, Supervisor- Related Commitment, and Gender. Emerging Leadership Journeys, 6, 13-44.

JAS-PT

JURNAL ANALISIS SISTEM PENDIDIKAN TINGGI

ISSN 2580 - 5339

Volume 1

Nomor 2

DESEMBER 2017

Hal $53-62$

FORUM DOSEN INDONESIA 